International Journal of Ophthalmology \& Eye Science (IJOES)

ISSN 2332-290X

\title{
The Correlation between Intracranial Pressure and Intraocular Pressure after Brain Surgery
}

Chunyu T ${ }^{1}$, Xiujun $\mathrm{P}^{1}$, Li N $\mathrm{N}^{2}$, Qin $\mathrm{L}^{1}$, Tian $\mathrm{Z}^{3}$

Research Article

${ }^{1}$ Eye Department, Navy General Hospital, 6 Fu Cheng Road, Beijing, China, 100037

${ }^{2}$ Department of Medical Statistics, The Third Affiliated Hospital of Peking University, \#49 North garden road, Haidian Dis, Beijing, China, 100191

${ }^{3}$ Neurosurgery Department, Navy General Hospital, 6 Fu Cheng Road, Beijing, China, 100037

\section{Abstract}

Objective: This study was to explore whether the intracranial pressure (ICP) changes and intraocular pressure (IOP) changes are synchronized after brain surgery. We also want to see whether measurement of IOP could be used to monitor ICP.

Materials and methods: We evaluated the correlation between intracranial pressure and intraocular pressure in 15 patients with meningioma admitted to our hospital. All patients required the intracranial pressure monitoring on clinical grounds. Intraocular pressures were measured by portable non-contact tonometer. We simultaneous recorded the intracranial pressure and intraocular pressure once a time per hour.

Results: We found significant correlation between intraocular pressures and intracranial pressure in $60.0 \%(9 / 15)$ of the tested population. However, ICP and IOP showed significant correlation only in $4(16.7 \%)$ out of 24 time points $(\mathrm{P}<0.05)$.

Conclusions: Although there is a significant correlation between ICP and IOP in neurosurgical patients, changes in IOP cannot always reflect the dynamic changes in ICP.

Keywords: Intracranial Pressure, Intraocular Pressure, The Translaminar Pressure Gradient

\section{*Corresponding Author:}

Chunyu Tian,

Eye Department, Navy General Hospital,

6 Fu Cheng Road, Beijing, China, 100037

E-mail: piscestcy@hotmail.com

Received: July 24, 2014

Accepted: August 16, 2014

Published: August 22, 2014

Citation: Chunyu T, et al. (2014). The correlation between intracranial pressure and intraocular pressure after brain surgery, Int J Ophthalmol Eye Res, 2(5), 54-58. doi: http://dx.doi.org/10.19070/2332290X-140008

Copyright: Chunyu $\mathbf{T}^{\circ}$ 2014. This is an open-access article distributed under the terms of the Creative Commons Attribution License, which permits unrestricted use, distribution and reproduction in any medium, provided the original author and source are credited.

\section{Introduction}

Intracranial pressure (ICP) measurement is used commonly in neurosurgery[1]. Currently, direct measurement of cerebrospinal fluid pressure by intraventricular monitor is considered to be the "gold standard" of ICP measurement[2]. However, attempts have been made to measure ICP by non-invasive methods such as transcranialdoppler, tympanic membrane displacement, and central venous pressure measurement[3-6]. Recently, some researcher raised the point that monitoring of IOP can be used to speculate ICP $[7,8]$. The interaction between ICP, which formed by cerebro- spinal fluid, and IOP, which formed by aqueous humor, has its theoretical basis of anatomy. However, other scholars believe that there is no contact between ICP and IOP $[9,10]$.

We wanted to know whether there is any relationship between the ICP changes and IOP changes. We also want to assess the 24 hours physiological curve of intracranial pressure and, intraocular pressure and answer the question that whether monitoring of IOP can be used to speculate ICP.

\section{Methods}

The study was performed in the Department of Neurosurgery and Ophthalmology, General Navy Hospital, Beijing, China between January 2009 and June 2013. Totally 15 patients who took the surgery treatment with diagnose of supratentorial meningioma were enrolled in our study. Patients were excluded if their meningioma bigger than $60 \mathrm{~mm} 2$, or they had pre-existing sever optic nerve edema, eye surgery, or were taking medications known to alter IOP. This prospective study was approved by the local ethics committee and conducted in accordance with the ethical principles described by the declaration of Helsinki. All participants signed a detailed informed consent form Invasive ICP measurement included intraventricular placement of the Microchip micro transducer (Codman, Johnson \& Johnson, Berkshire, UK) in the operating room. The tip of the micro transducer was positioned 3-4 cm within the brain parenchyma via a frontal burr hole. ICP Express Monitor interface (Codman \&Shurtleff Inc., Raynham, MA, USA) was used for measurement. A value of $14 \mathrm{mmHg}$ was regarded as the cut-off for normal ICP. Patients' IOP were meas- 
ured by a portable pneumatonometer (Model 30 ${ }^{\mathrm{TM}}$, Reichert Inc., of Buffalo, NY), which provides fast and accurate IOP measurement. Patients had their IOP measured pre hour a day, and each time a mean pressure was calculated for each eye. The Pneumatonometer has a standard deviation along with IOP measurement. To increase diagnostic accuracy, only measurements that had a standard deviation less than $5 \mathrm{mmHg}$ were accepted. A value of $21 \mathrm{mmHg}$ was regarded as the cut-off for normal IOP.

\section{Statistical analysis}

All data are presented as mean \pm standard deviation (SD). Data are consistent with a normal distribution, Pearson correlation test were performed between IOP and ICP, 95\% CI were determined and $\mathrm{p}<0.05$ was regarded as statistically significant. Time series analyses were also performed in this study. Statistical calculations were performed using the SPSS 21 statistical package (SPSS for Windows, Chicago, IL).

\section{Results}

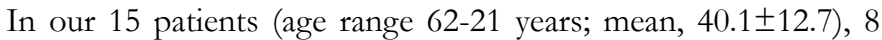
cases $(53.3 \%)$ were man and 7 cases $(46.7 \%)$ were women. Meningioma located in prefrontal (6 cases, $40.0 \%$ ), temporallobe ( 7 cases, $46.7 \%$ ) and parietal (2 cases, $13.3 \%$ ). The sizes of meningioma range from 18 to $60 \mathrm{~mm} 2$ (Table 1). Mean measured ICP was $13.8 \pm 4.7 \mathrm{mmHg}$ (range from 5.0 to $29.0 \mathrm{mmHg}$ ). Mean IOP was $26.0 \pm 5.9 \mathrm{mmHg}$ (range from 13.8 to $42.0 \mathrm{mmHg}$ ). All patients' characters and Pearson correlation coefficients are presented in Table 1 . Out of the 15 patients, 7 patients $(46.7 \%)$ had a very significant $(\mathrm{p}<0.01)$ correlation of ICP to IOP; 2 patients $(13.3 \%)$ had significant $(\mathrm{p}<0.05)$ correlation of ICP to IOP.

Both ICP and IOP showed their spontaneous rhythmic fluctuations (Fig 1 and Fig 2). Table 2 presents the 24-hour change patterns in ICP and IOP. The max ICP appeared at $8 \mathrm{AM}$ (Mean \pm SD, $17.7 \pm 0.9 \mathrm{mmHg}$; $95 \% \mathrm{CI}, 15.7$ to $19.6 \mathrm{mmHg}$ ). However the max IOP presented at $9 \mathrm{AM}$ (Mean $\pm \mathrm{SD}, 30.7 \pm 1.2 \mathrm{mmHg}$; 95\% CI, 27.9 to $33.1 \mathrm{mmHg}$ ). The min ICP presented at $7 \mathrm{PM}$ (Mean \pm SD, $11.3 \pm 1.1 \mathrm{mmHg}$; $95 \% \mathrm{CI}, 8.9$ to $13.6 \mathrm{mmHg}$ ). However the min IOP presented at $2 \mathrm{AM}$ (Mean $\pm \mathrm{SD}, 22.3 \pm 1.0 \mathrm{mmHg} ; 95 \% \mathrm{CI}$, 20.1 to $24.5 \mathrm{mmHg}$ ). ICP and IOP showed significant correlation only in $4(16.7 \%)$ out of 24 time points $(\mathrm{P}<0.05$, Table 2$)$.

\section{Discussion}

We evaluated the correlation between intracranial pressure and intraocular pressure in 15 patients with meningioma admitted to our hospital, and found that $9(60.0 \%)$ out of 15 patients had significant correlation of ICP to IOP $(\mathrm{P}<0.05$, Table 1$)$. We also found that although there is a significant correlation between ICP and IOP in neurosurgical patients, changes in IOP cannot always reflect the dynamic changes in IOP (Table 2).

Recently, some scholars have conducted clinical studies on ICP and IOP relationship[11,12]. Theoretically, an increase in ICP could be transmitted to the optic nerve, and thus indirectly to the eye itself. In 2006, Sajjadi demonstrated a significant correlation between IOP and ICP in a prospective cohort study for various neurologic workups[8]. They reported a close correlation $(r=0.955)$, with a nearly 1:1 relation between IOP and ICP.

Table 1. Basic characteristics of patients (ICP: Intracranial pressure; IOP: Intraocular pressure; $* \mathrm{P}<0.05 ; * * \mathrm{P}<0.01$ )

\begin{tabular}{|l|l|l|l|l|l|l|}
\hline Pat & Age & Gender & Location & Size & Treatment & ICP \& IOP Pearson correlation \\
\hline 1 & 21 & M & Prefrontal & 18 & Full & $0.415^{*}$ \\
\hline 2 & 43 & F & Temporal lobe & 48 & Partial resection & $0.502^{*}$ \\
\hline 3 & 54 & M & Prefrontal & 37 & Full & 0.046 \\
\hline 4 & 27 & M & Temporal lobe & 29 & Full & $0.728^{* *}$ \\
\hline 5 & 35 & F & Parietal & 55 & Partial resection & $0.529^{* *}$ \\
\hline 6 & 37 & F & Temporal lobe & 42 & Partial resection & 0.078 \\
\hline 7 & 42 & M & Prefrontal & 39 & Full & 0.379 \\
\hline 8 & 28 & F & Parietal & 40 & Full & $0.528^{* *}$ \\
\hline 9 & 49 & F & Prefrontal & 60 & Partial resection & $0.622^{* *}$ \\
\hline 10 & 58 & F & Temporal lobe & 31 & Partial resection & 0.337 \\
\hline 11 & 36 & M & Temporal lobe & 25 & Full & $0.758^{* *}$ \\
\hline 12 & 30 & F & Temporal lobe & 33 & Full & $0.826^{* *}$ \\
\hline 13 & 27 & M & Prefrontal & 45 & Full & $0.835^{* *}$ \\
\hline 14 & 62 & M & Prefrontal & 57 & Partial resection & 0.34 \\
\hline 15 & 53 & M & Temporal lobe & 20 & Full & 0.261 \\
\hline
\end{tabular}

However, their IOP measurements were performed with Schiotz tonometer, and the accuracy needs to be improved. Lashutka also found a positive correlation between elevated IOP and ICP in a prospective observational pilot study[7]. They found that all the patients with an abnormal ICP had an abnormal IOP; similarly, all patients with a normal ICP had a normal IOP (sensitivity 1.00, 95\% CI 0.86-1.0; specificity 1.0, 95\% CI 0.93-1.0). However, the study participants were admitted neurosurgical intensive care unit patients with previously placed invasive ICP monitors. Therefore, there is an inherent selection bias in using the ICU setting because these patients are critically ill with conditions predisposing them to elevated intracranial pressure. In 2009, Czarnik and colleagues found no relationship between ICP and IOP when measured simultaneously in an intensive care setting among comatose patients on continuous ICP measuring[9]. They enrolled comatose patients admitted to the emergency department with traumatic and non-traumatic brain injuries such as, subarachnoid haemorrhage and spontaneous intracerebral haemorrhage. ICP in 
Figure 1. Recorded curves of 9 out of 15 patients, which showed significant correlation between ICP and IOP ( $\mathrm{p}<0.05$ ).

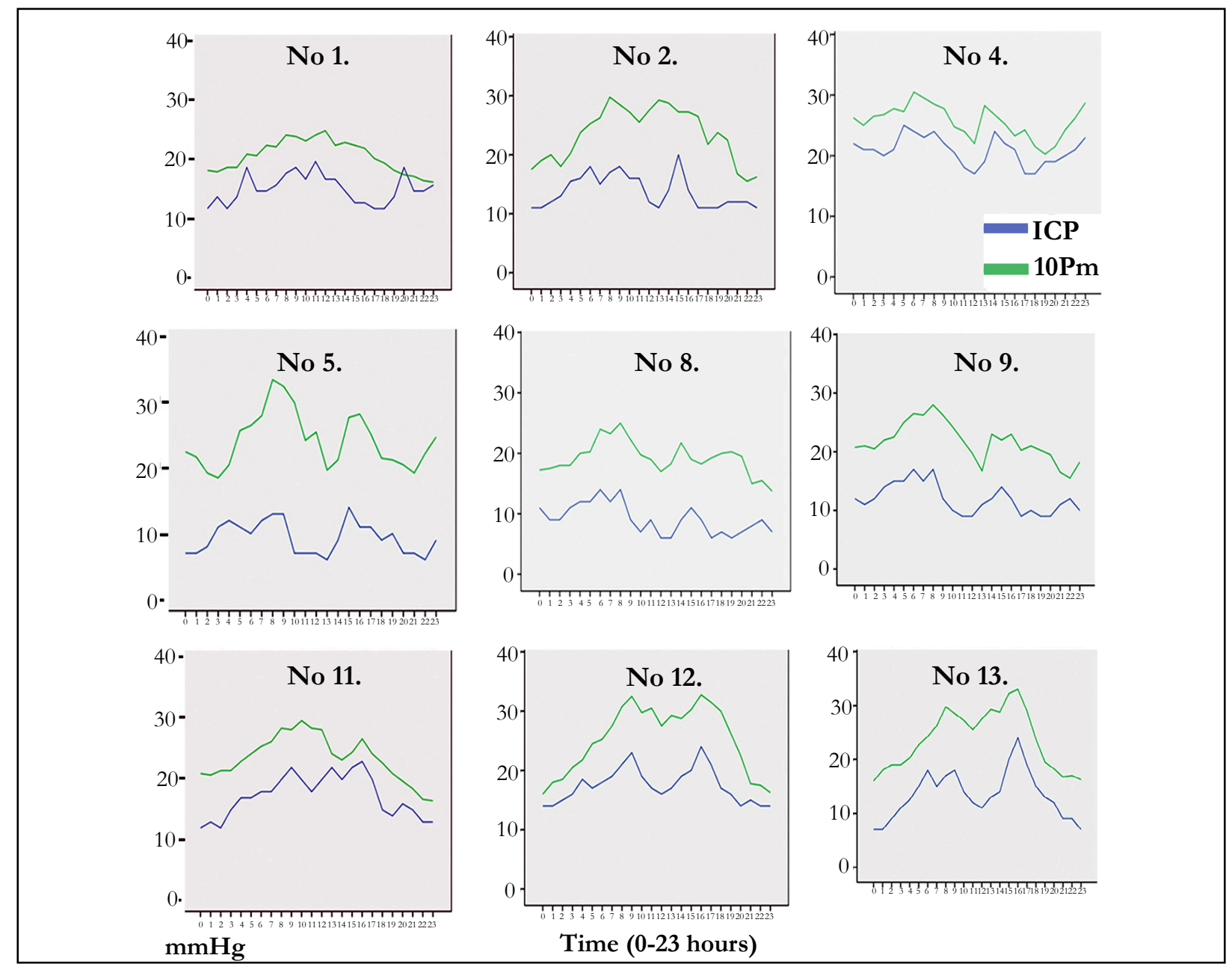

Figure 2 Recorded curves of 6 out of 15 patients, which did not show significant correlation between ICP and IOP $(\mathrm{P} \geq 0.05)$.

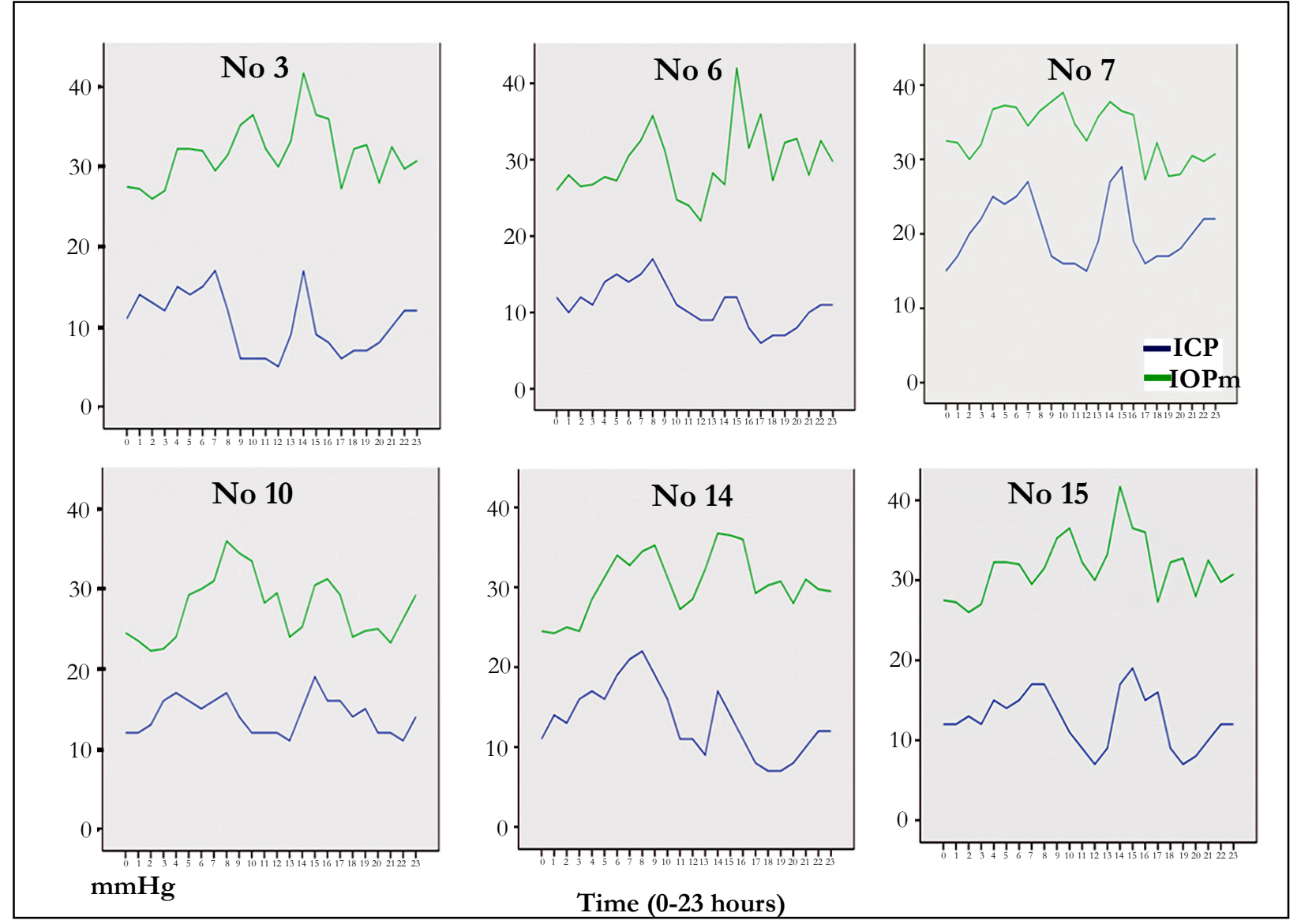


Table 2. The correlation between ICP and IOP in a day (ICP: Intracranial pressure; IOP: Intraocular pressure; $* \mathbf{P}<0.05 ; * * \mathbf{P}<0.01$ )

\begin{tabular}{|c|c|c|c|c|c|}
\hline Time & ICP & $95 \% \mathrm{CI}$ & IOPm & $95 \% \mathrm{CI}$ & $\begin{array}{l}\text { ICP \& IOP Pear- } \\
\text { son correlation }\end{array}$ \\
\hline 0 & $11.87 \pm 0.93$ & 9.88 to 13.85 & $22.35 \pm 1.30$ & 19.56 to 25.14 & 0.409 \\
\hline 1 & $12.2 \pm 0.96$ & 10.13 to 14.26 & $22.58 \pm 1.19$ & 20.02 to 25.14 & 0.465 \\
\hline 2 & $12.73 \pm 0.96$ & 10.67 to 14.80 & $22.33 \pm 1.02$ & 20.14 to 24.53 & $0.710^{* *}$ \\
\hline 3 & $14.07 \pm 0.89$ & 12.16 to 15.96 & $22.67 \pm 1.15$ & 20.20 to 25.13 & $0.578^{*}$ \\
\hline 4 & $16.17 \pm 0.92$ & 14.19 to 18.14 & $25.05 \pm 1.41$ & 22.02 to 28.08 & $0.560^{*}$ \\
\hline 5 & $15.93 \pm 1.0$ & 13.78 to 18.09 & $26.73 \pm 1.26$ & 24.02 to 29.44 & 0.453 \\
\hline 6 & $16.8 \pm 1.03$ & 14.59 to 19.0 & $28.20 \pm 1.13$ & 25.77 to 30.63 & 0.474 \\
\hline 7 & $17.0 \pm 1.06$ & 14.7 to 19.28 & $28.17 \pm 0.93$ & 26.16 to 30.17 & $0.638^{*}$ \\
\hline 8 & $17.67 \pm 0.90$ & 15.73 to 19.60 & $30.47 \pm 1.01$ & 28.57 to 32.90 & 0.157 \\
\hline 9 & $15.8 \pm 1.24$ & 13.13 to 18.46 & $30.73 \pm 1.21$ & 27.88 to 33.06 & 0.049 \\
\hline 10 & $13.3 \pm 1.22$ & 10.67 to 15.93 & $28.98 \pm 1.43$ & 25.91 to 32.06 & -0.033 \\
\hline 11 & $12.47 \pm 1.12$ & 10.04 to 14.89 & $26.63 \pm 1.12$ & 24.22 to 29.04 & 0.094 \\
\hline 12 & $11.40 \pm 1.14$ & 8.94 to 13.86 & $25.98 \pm 1.11$ & 23.60 to 28.36 & 0.183 \\
\hline 13 & $12.33 \pm 1.27$ & 9.59 to 15.08 & $26.76 \pm 1.54$ & 23.45 to 30.08 & 0.228 \\
\hline 14 & $15.87 \pm 1.32$ & 13.04 to 18.69 & $28.83 \pm 1.88$ & 24.80 to 32.86 & 0.505 \\
\hline 15 & $17.00 \pm 1.39$ & 14.03 to 19.98 & $29.77 \pm 1.76$ & 25.98 to 33.55 & 0.106 \\
\hline 16 & $15.00 \pm 1.48$ & 11.83 to 18.16 & $29.23 \pm 1.54$ & 25.93 to 32.54 & 0.135 \\
\hline 17 & $12.73 \pm 1.35$ & 9.84 to 15.63 & $26.27 \pm 1.19$ & 23.71 to 28.83 & 0.146 \\
\hline 18 & $11.40 \pm 1.02$ & 9.21 to 13.58 & $25.15 \pm 1.29$ & 22.38 to 27.92 & -0.08 \\
\hline 19 & $11.27 \pm 1.09$ & 8.93 to 13.60 & $24.60 \pm 1.41$ & 21.58 to 27.62 & -0.379 \\
\hline 20 & $11.60 \pm 1.12$ & 9.18 to 14.01 & $23.23 \pm 1.23$ & 20.60 to 25.87 & -0.277 \\
\hline 21 & $12.07 \pm 1.03$ & 9.86 to 14.28 & $22.47 \pm 1.73$ & 18.75 to 26.18 & 0.14 \\
\hline 22 & $12.53 \pm 1.10$ & 10.17 to 14.89 & $22.52 \pm 1.74$ & 18.79 to 26.24 & 0.287 \\
\hline 23 & $12.67 \pm 1.20$ & 10.09 to 15.24 & $23.00 \pm 1.82$ & 19.09 to 26.91 & 0.443 \\
\hline
\end{tabular}

such patients is generally more volatile, so there is also an inherent selection bias. In addition, they only measure IOP 3 times a day, which can not reflect the physiological fluctuations in intraocular pressure of the day, and do not accurately reflect the intracranial effects of intraocular pressure. When we design the study, give full consideration to avoid these limitations. First, we enrolled patients who diagnosised as supratentorial meningioma size less than $60 \mathrm{~mm} 2$ without obviously optic nerve edema. Because supratentorial meningiomas are benign tumors, changes in ICP are not as volatile as traumatic brain injury, and avoid the oppression of the tumor to the optic foramen. Second, patients' IOP were measured by a portable pneumatonometer per hour a day. We could get enough dynamic data of IOP and get physiological changes in the curve of the day.

We found a highly significant correlation between IOP and ICP within patients, but a significant variability in the value of this relation between patients. In 6 out of the 15 patients studied, the correlation between IOP and ICP was not significant (Table 1). In these patients the translaminar pressure difference (TLPD, the difference in IOP and ICP across the lamina cribrosa) is much higher than the others. And the fluctuation curve of ICP and IOP cannot coincide simultaneously. The max ICP and IOP presented at different time, the same as the min ICP and IOP. ICP and IOP showed significant correlation only in $4(16.7 \%)$ out of 24 time points $(\mathrm{P}<0.05$, Table 2$)$. Therefore, changes in IOP were an insensitive indicator of changes in ICP, so the use of IOP with current methods as a non-invasive monitor of ICP is unlikely. We hypothesized that there were two possible ways of interaction between ICP and IOP. First, there was the anatomical proximity of the eye and the intracranial space[13]. Optic nerve sheath is surrounded by cerebrospinal fluid (CSF), which formed ICP. So it is a probable mechanism of direct pressure transmission through CSF exactly at the point where the optic nerve enters the orbit. The second mechanism was pressure transmission through the venous and/or arterial system of the brain and the ocular bulb to the intraocular fluid[14]. In both kinds of possible mechanisms, it requires some time to see the changes of ICP affecting IOP. On the function curve of time series analysis, we could also see the same delayed reaction of ICP and IOP (Fig 1 and Fig 2). There are $86.7 \%$ percent $(13$ cases) of patients had temporary increased ICP in our study. However all the cases had temporary high IOP. Another clinical value of our research is that after reducing ICP to normal, perhaps reducing of IOP is still needed. Research on latency and mechanisms still need to be done with large samples.

\section{References}

[1] VanderlindenRG, Chisholm LD (1974) Vitreous hemorrhages and sudden increased intracranial pressure. J Neurosurg 41:167-176.

[2] Lesniak MS, Clatterbuck RE, Rigamonti D, Williams MA (2002) Low pressure hydrocephalus and ventriculomegaly: hysteresis, non-linear dynamics, and the benefits of CSF diversion. Br J Neurosurg 16:555-561.

[3] Czarnik T, Gawda R, Latka D, Kolodziej W, Sznajd-Weron K, et al. (2007) Noninvasive measurement of intracranial pressure: is it possible. J Trauma 
62:207-211.

[4] Easa D, Tran A,Bingham W (1983) Noninvasive intracranial pressure measurement in the newborn. Am J Dis Child 137:332-335.

[5] Salman MS (1997) Can intracranial pressure be measured non-invasively?. Lancet 350:1367.

[6] Hayreh SS (1998) Non-invasive measurement of intracranial pressure. Lancet 351:524-525.

[7] Lashutka MK, Chandra A, Murray HN, Phillips GS,Hiestand BC (2004) The relationship of intraocular pressure to intracranial pressure. Ann Emerg Med 43:585-591.

[8] Sajjadi SA, Harirchian MH, Sheikhbahaei N, Mohebbi MR, Malekmadani $\mathrm{MH}$, et al (2006) The relation between intracranial and intraocular pressures: study of 50 patients. Ann Neurol 59:867-870.

[9] Czarnik T, Gawda R, Kolodziej W, Latka D, Sznajd-Weron K, et al (2009) Associations between intracranial pressure, intraocular pressure and mean arterial pressure in patients with traumatic and non-traumatic brain injuries.
Injury 40:33-39.

[10] Golan S, Kurtz S, Mezad-Koursh D, Waisbourd M, Kesler A, et al (2013) Poor correlation between intracranial pressure and intraocular pressure by hand-held tonometry. Clin Ophthalmol 7:1083-1087.

[11] Muchnok T, Deitch K ,Giraldo P (2012) Can intraocular pressure measurements be used to screen for elevated intracranial pressure in emergency department patients?. J Emerg Med 43:532-537.

[12] Sheeran P, Bland JM, Hall GM (2000) Intraocular pressure changes and alterations in intracranial pressure. Lancet 355:899.

[13] Morgan WH, Yu DY,Balaratnasingam C (2008) The role of cerebrospinal fluid pressure in glaucoma pathophysiology: the dark side of the optic disc. J Glaucoma 17:408-413.

[14] Morgan WH (2013) Central venous pulsations: new findings, clinical importance and relation to cerebrospinal fluid pressure. J Glaucoma 22:S15-16. 